
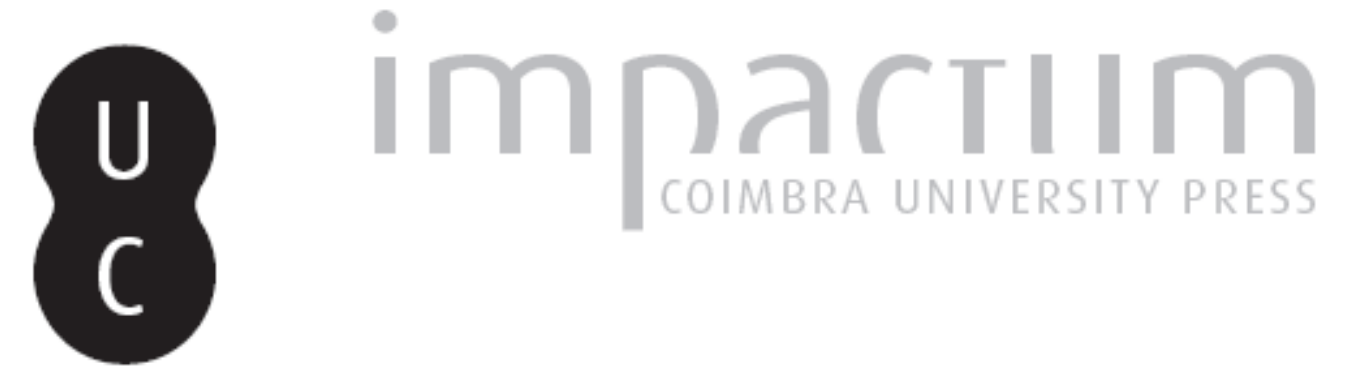

\title{
Uma modernidade perdida: da melancolia à alegria racional na antropologia do homem superior, segundo D. Duarte
}

Autor(es): $\quad$ Carvalho, Mário Santiago de Publicado por: Faculdade de Letras da Universidade de Coimbra, Instituto de Estudos

URL

persistente:

DOI: $\quad$ DOI:http://dx.doi.org/10.14195/0872-0851_43_7

Accessed : $\quad$ 26-Apr-2023 11:54:06

A navegação consulta e descarregamento dos títulos inseridos nas Bibliotecas Digitais UC Digitalis, UC Pombalina e UC Impactum, pressupõem a aceitação plena e sem reservas dos Termos e Condições de Uso destas Bibliotecas Digitais, disponíveis em https://digitalis.uc.pt/pt-pt/termos.

Conforme exposto nos referidos Termos e Condições de Uso, o descarregamento de títulos de acesso restrito requer uma licença válida de autorização devendo o utilizador aceder ao(s) documento(s) a partir de um endereço de IP da instituição detentora da supramencionada licença.

Ao utilizador é apenas permitido o descarregamento para uso pessoal, pelo que o emprego do(s) título(s) descarregado(s) para outro fim, designadamente comercial, carece de autorização do respetivo autor ou editor da obra.

Na medida em que todas as obras da UC Digitalis se encontram protegidas pelo Código do Direito de Autor e Direitos Conexos e demais legislação aplicável, toda a cópia, parcial ou total, deste documento, nos casos em que é legalmente admitida, deverá conter ou fazer-se acompanhar por este aviso. 


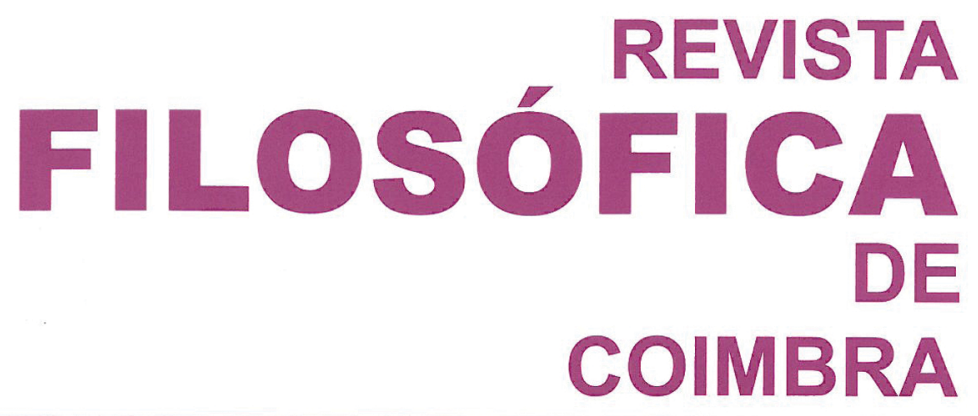

vol. 22 - número 43 - março 2013

vol. 22 - número 43 - março 2013

Fundação Eng. António de Almeida

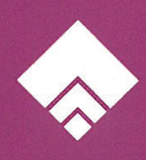




\title{
UMA MODERNIDADE PERDIDA. DA MELANCOLIA À ALEGRIA RACIONAL NA ANTROPOLOGIA DO HOMEM SUPERIOR, SEGUNDO D. DUARTE
}

\author{
MÁRIO SANTIAGO DE CARVALHO*
}

\begin{abstract}
Resumo: O 'Leal Conselheiro', principal obra do rei D. Duarte, não tem, inexplicavelmente, concitado a atenção dos historiadores europeus da filosofia medieval. Serve este artigo como fundo de uma proposta de leitura, a de que importa dar mais relevância ao tópico da cura da melancolia do que ao da demanda hermenêutica de uma qualquer configuração da cultura portuguesa. Sublinha-se o carácter original, criativo e positivo da semântica e do horizonte filosófico que determinou as obras do autor. Os tópicos da vontade, do poder, do saber e da experiência surgem aqui como chaves de uma proposta que se poderia ter erguido como moderna e, por isso, alternativa à configuração da modernidade tal como a conhecemos em filosofia.
\end{abstract}

Palavras-chave: D. Duarte, Leal Conselheiro, melancolia, vontade, poder, saber, alegria, modernidade.

Résumé: Dans la production philosophique des laïcs l'oeuvre introspective du philosophe-roi D. Duarte (1438), Leal Conselheiro - une absence inexplicable dans l'herméneutique plus spécialisée européenne anciennne ou nouvelle - est digne d'attention. La tradition aristotélicienne et thomiste est au centre de son ouvrage, mais la réflexion aussi personnelle de l'auteur dans un context culturel tout à fait particulier, a produit un travail très original et créatif concernant surtout la volonté, l'intellect, la vertue, le pouvoir, le savoir et l'expérience. Une

* Departamento de Filosofia, Comunicação e Informação da Faculdade de Letras da Universidade de Coimbra. O presente artigo é uma versão portuguesa ampliada da comunicação apresentada pelo autor ao XIII ${ }^{\circ}$ Congresso de Filosofia Medieval, "Pleasures of Knowledge", organizado pela Universidade Ludwig-Maximilians de Munique para a S.I.E.P.M., em Freising (agosto de 2012), na ocasião com o título "Sublime mélancholie. Le (dé-)plaisir de la connaissance selon le roi Edouard". 
logique axée sur la puissance de la volonté a un noyau d'interprétation dont il faut s'atarder avec attention et dont la modernité on ne devrait pas oublier.

Mots-clefs: D. Duarte, Leal Conselheiro, mélancholie, volonté, pouvoir, savoir, joie, modernité.

1.

Antes mesmo da língua alemã - penso na perplexidade do secretário de Nicolau de Cusa (+1464), João André de Bussi ${ }^{1}-$, o idioma português que «todo seja portugues escripto» como ordena El-Rei D. Duarte ${ }^{2}$ - entra na filosofia com um tom de modernidade e de uma maneira que merece atenção, mas não tem sido devidamente atendida na produção europeia especializada. Tal entrada dá-se, pelo menos, por dois veios alternativos, quer à Universidade (1288/1290), quer aos maiores centros culturais do país (Santa Cruz de Coimbra, 1131 e Mosteiro de Alcobaça, 1248/51), quer ainda aos vários "studia" das ordens mendicantes (séc. XIV) ${ }^{3}$. Esses dois eixos são, alfim, a corte régia - onde papel saliente desempenhou a chamada Geração de Avis ou os filhos de D. João I - e alguma produção sobretudo oriunda de vários mosteiros. Dirigindo-se ambos estes últimos filões a leigos - e inexplicavelmente desconhecidos pelos trabalhos mais especializados $^{4}$ - alguns textos de espiritualidade em língua portuguesa parecem veicular um modelo não de todo incompatível com o horizonte do "idiota de mente" 5 . Urge, por isso, calibrar para ocidente a geografia

${ }^{1}$ Cf. H. Günther, Le Temps de l'Histoire. Expérience du monde et catégories temporelles en philosophie de l'histoire de saint Augustin à Pétrarque, de Dante à Rousseau, Trad., Paris, 1995, pp. 107 (para maior pormenorização deste assunto vd. M.S. de Carvalho, O Problema da habitação. Estudos de (História da) Filosofia, Lisboa-Coimbra: Ed. Colibri- FLUC, 2002, p. 43).

${ }^{2}$ D. Duarte, Livro dos Conselhos de El-Rei D. Duarte (Livro da Cartuxa). Ed. diplomática de J.J. Alves Dias, Lisboa: Editorial Estampa, 1982, c. 30, p.151; aqui doravante sempre referida como Cartuxa logo seguida do capítulo e da página; lateralmente embora veja-se também D. Duarte, Leal Conselheiro. Ed. crítica, introd. e notas de Ma Helena L. de Castro, Lisboa: INCM, 1998, XCIX: 362 (de onde citamos e para onde remetemos sempre, identificado como: Conselheiro seguido da indicação do capítulo e da página).

${ }^{3}$ Cf. M. S. de Carvalho, "Conspecto do Desenvolvimento da Filosofia em Portugal (Séculos XIII - XV)”, Revista Española de Filosofía Medieval 4 (1997), pp. 131-155.

${ }^{4}$ Cf. R. Imbach, Laien in der Philosophie des Mittelalters. Hinweise und Anregungen zu einem vernachlässigten Thema, Amsterdam: B.R. Grüner, 1989; vd. ainda L. Sturlese (a cura di), Filosofia in volgare. Atti del Colloquio Internazionale de la S.I.S.P.M., Louvain-la-Neuve: FIDEM, 2003. Vd. Obras dos Príncipes de Avis. Introd. e Revisão de M. Lopes de Almeida, Porto: Lello \& Ir., 1981.

${ }^{5}$ Cf. Nicholas of Cusa, The Layman on Wisdom and the Mind. Translated, with an Introduction and notes by M.L. Führer, Ottawa: Dovehouse Ed., 1989. Sobre este autor em 
que S. Swiezawsky reconstruiu com exclusividade para o seu leste europeu quatrocentista ${ }^{6}$.

Apesar do próprio D. João I (1385-1433) ter impulsionado a tradução na sua corte $^{7}$, a entrada da língua portuguesa em certo tipo de erudição ou de especialização é anterior aos séculos XIV e XV. O rei trovador D. Dinis (1279-1325) não instituiu só o idioma português como língua de chancelaria ${ }^{8}$. Também encomendava que se escrevesse (1318) sobre saberes práticos, quais as doenças de cavalos ${ }^{9}$ ou a altanaria, matéria de que se encarregou o falcoeiro real João Martins Perdigão ${ }^{10}$. Esta última área será, compreensivelmente privilegiada, razão pela qual também o rei D. Fernando (1367-1383) rogará a Pero Merino o seu Livro da Falcoaria. Juntamente com o Livro da Montaria de D. João $\mathrm{I}^{11}$ e com o primeiro tratado de equitação da literatura europeia, da autoria de D. Duarte ${ }^{12}$, a

português vd. o sempre imprescindível J.Ma André, Sentido, simbolismo e interpretação no discurso filosófico de Nicolau de Cusa, Coimbra: FCG - JNICT, 1997.

${ }^{6}$ Stefan Swiezawski, Histoire de la philosophie européenne au XVe siècle, adaptée par Mariusz Prokopowicz, traduit du polonais, Paris : Editions Beauchesne, 1990. Sobre a "geografia" vd. M.S. de Carvalho, "Acidentais ocidentes e a surdez de Aristóteles. Para uma geografia da Filosofia" Biblos n.s. 2 (2004), pp. 189-218; a mesma noção foi depois também utilizada e alargada por L. Sturlese, "Universality of Reason and Plurality of Philosophies in the Middle Ages. geography of Readers and Isograph of Text Diffusion before the Invention of Printing" o próprio artigo de abertura de Universalità della Ragione. Pluralità delle filosofie nel Medioevo (a cura di A. Musco et al.), Atti di XII Congresso Internazionale di Filosofia Medievale da la S.I.E.P.M.. Palermo, 17-22 settembre 2007, vol I.

${ }^{7}$ Fernão Lopes, Crónica de D. João I, edição preparada por M. Lopes de Almeida e A. de Magalhães Bastos, Porto: Livraria Civilização - Editora, 1990; vd. S.T. de Pinho, "O Infante D. Pedro e a 'escola' de tradutores da Corte de Avis", Biblos 69 (1993), pp. 129-153.

${ }^{8}$ Duarte Nunes de Leão, Chronica del Rei Dom Dinis, in Crónicas dos Reis de Portugal, Porto, Lello \& Irmão Ed., 1975, p. 236

9 Cf. R. Lapa, "Introdução", in Livro de Falcoaria de Pero Menino publicado com introd., notas e glossário por Rodrigues Lapa, Coimbra: Imprensa da Universidade, 1931, p. XII.

${ }^{10}$ Livro de Falcoaria... c. 24, p. 67.

${ }^{11}$ Cf. Libro de Montería composto pólo Señor Rey Don Joaom de Portugal, e dos Algarves, e Señor de Ceuta, in Obras dos Príncipes de Avis..., pp. 1-232; vd. S. Lima, «O desporto e a experiência na Idade Média», in Id., Obra Completa, Lisboa: FCG, 2002, pp. 1049-60. Poder-se-á ainda ver: Alfonso XI, Libro de la Montería. Estúdio y edición crítica por Maria Isabel Montoya Ramírez, Granada: Univ. de Granada, 1992.

12 J.M. Piel, «Prefácio», in D. Duarte, Livro da Ensinança de Bem Cavalgar Toda Sela que fez El-Rey Dom Eduarte. Ed. crítica, notas e glossário de J. M. Piel, Lisboa, Liv. Bertrand, 1944, p. viii (nova ed. facsimilada: Lisboa, INCM, 1986); aqui doravante sempre identificada como: Ensinança, seguida da identificação da parte, do capítulo e da 
que adiante aludiremos, este complexo literário inaugura, no seu género naturalista, o que virá a ser uma tradição de cultura da experiência veiculada em linguagem.

Tudo isto nos ajuda a compreender que, depois de Dante $(+1321)$ ter glosado a importância da sua língua materna, comparando-a ao pão mais pobre embora acessível a um maior público ${ }^{13}$, o faça também o Infante D. Pedro $(+1449)$, baseando-se, por seu lado, na maior difusão do idioma português no território ${ }^{14}$. Concomitantemente, mas fora dos círculos palacianos, compunham-se, ainda na primeira metade do século $\mathrm{XV}$, um conjunto de obras sobre outras dimensões da experiência, quais a mística e a apologética, em títulos notáveis como o Horto do Esposo ${ }^{15}$, O Boosco Deleitoso Solitário ${ }^{16}$ e o Livro da Corte Imperial ${ }^{17}$.

2.

Interessa-nos aqui a obra do undécimo rei português, D. Duarte (1433-1438) ${ }^{18}$, sobretudo o Leal Conselheiro $(1435 / 38)^{19}$, ao qual agregaremos também o Livro da Ensinança de Bem Cavalgar toda a Sela

página; também Ensinança, Prólogo, p. 3; Livro de Falcoaria... c. 24, p. 67: “... em o comesso deste livro disse que en elle nom escrevera outra cousa, salvo aquella que hey feito per minha mão..."

13 Dante, De ulgari eloquentia I xiii; vd. M.S. de Carvalho, O problema da habitação... pp. 44-46; R. Imbach, Dante, la philosophie et les laïcs, Fribour Paris: Cerf, 1996, p. 137.

${ }^{14}$ Cf. Livro dos Ofícios de Marco Tullio Ciceram, o qual tornou em linguagem o Infante D. Pedro, duque de Coimbra. Ed. crítica segundo o ms. de Madrid, prefaciada, anotada e acompanhada de glossário por Joseph Piel, Coimbra: Acta Universitatis Conimbrigensis, 1948. Pode ver-se também in Obras dos Príncipes de Avis... pp. 765-884; citamos da dedicatória (ibid. p. 769): “... e nom embargando que o latim na christandade he mais geeral que o português, em Portugal esta linguagem he mais geeral que o latim..."

15 Cf. Horto do Esposo, edição crítica de Irene Freire Nunes, Lisboa: Edições Colibri, 2007.

${ }^{16}$ Cf. Boosco Deleitoso, edição de Augusto Magne, Rio de Janeiro: Ministério da Educação, 1950.

${ }^{17}$ Cf. Corte Enperial, edição interpretativa de Adelino de Almeida Calado, s.1.: Universidade de Aveiro, 2000.

18 Cf. Luís Miguel Duarte, D. Duarte. Requiem por um Rei Triste, Rio de Mouro: Círculo de Leitores, 2007.

${ }_{19}$ D. Duarte, Leal Conselheiro. Ed. crítica, introd. e notas de $\mathrm{M}^{\mathrm{a}}$ Helena L. de Castro, Lisboa: INCM, 1998; vd. ainda: Leal Conselheiro o qual fez Dom Eduarte, Rey de Portugal e do Algarve e Senhor de Cepta. Ed. crítica e anotada por J.M. Piel, Lisboa: Liv. Bertrand, 1942 (doravante citado, para a distinguir da edição previamente citada, como: Leal Conselheiro). 
$(1433 / 38)^{20}$ e os apontamentos registados no Livro da Cartuxa $(1423 / 38)^{21}$. Descoberto, o primeiro dos títulos mencionados, em 1804 pelo Abade Correia da Serra na Biblioteca Real de Paris, o Leal Conselheiro só foi publicado pela primeira vez no início da década de 40 do século XIX. O mesmo sucedeu com o Livro da Ensinança, editado em 1842, enquanto a edição integral do Livro da Cartuxa teve de aguardar mais de cem anos. Repare-se como nesse mesmo século português, uma centúria entre nós marcada pelos ideais de liberdade e de igualdade, o escritor liberal Almeida Garrett, retratando D. Duarte, ressalte o "seu coração angélico onde morou toda a virtude" 22 . Mercê do idioma em que foram escritas, estas obras têm concitado quase exclusivamente a atenção dos especialistas portugueses ${ }^{23}$, e, decerto, pode asseverar-se sem medo de errar que o Leal Conselheiro de D. Duarte, juntamente com o título do seu irmão D. Pedro, $A$ Virtuosa Benfeitoria ${ }^{24}$, marcam já não a entrada mas o princípio da consolidação da língua portuguesa como idioma filosófico ${ }^{25}$. A este respeito, e sem esquecermos sobretudo os estudos de F. da Gama Caeiro, de $\mathrm{M}^{\mathrm{a}}$ Cândida Pacheco ou de $\mathrm{M}^{\mathrm{a}}$ Helena da Rocha Pereira, deveríamos juntar o interesse, ainda por aprofundar, de temáticas e semânticas relativas, entre outros temas mais, à phronesis, à scientia transcendens

${ }^{20}$ D. Duarte, Livro da Ensinança de Bem Cavalgar Toda Sela que fez El-Rey Dom Eduarte. Ed. crítica, notas e glossário de J. M. Piel, Lisboa, Liv. Bertrand, 1944 (nova ed. facsimilada: Lisboa, INCM, 1986); sobre esta obra vd. W. Giese, "Portuguiesisches Reitzeug am Anfang des XV. Jahrhunderts nach D. Duartes 'Livro da Ensinança de bem cavalgar toda sella"”, in AA.VV., Miscelânea Scientífica e Literária dedicada ao Doutor J. Leite de Vasconcelos, Coimbra, Imprensa da Universidade, vol. I, pp. 67-84; S. Lima, «O desporto, o medo e El-Rei D. Duarte», in Id., Obra Completa, Lisboa: FCG, 2002, pp. 979-986.

${ }^{21}$ D. Duarte, Livro dos Conselhos de El-Rei D. Duarte (Livro da Cartuxa). Ed. diplomática de J.J. Alves Dias, Lisboa: Editorial Estampa, 1982.

22 A. Garrett, Da Educação VIII, ed. Obras Completas. Vol. XIII, Discolivro: Camarate, 1984, p. 186.

${ }^{23}$ Bibliografia básica sobre o autor in A. Botelho, D. Duarte, Lisboa: Verbo, 1993; J. Gama, A filosofia da cultura portuguesa no Leal Conselheiro de D. Duarte, Lisboa: FCG-JNICT, 1995.

24 D. Pedro \& Frei João Verba, O Livro da Virtuosa Benfeitoria. Ed. crítica, introd. e notas de Adelino de A. Calado, Coimbra: Acta Universitatis Conimbrigensis, 1994.

25 Cf., para o Leal Conselheiro, F. da G. Caeiro, "Dom Duarte à luz da cultura portuguesa" e Ma C. Pacheco, "Para uma antropologia situada: O Leal Conselheiro" Revista Portuguesa de Filosofia 67 (1991), p. 407-424 e p. 425-441, respectivamente; para $A$ Virtuosa Benfeitoria, M ${ }^{\mathrm{a}}$ H. da R. Pereira, "Helenismos no Livro da Virtuosa Benfeitoria", Biblos 57 (1981), p. 313-358; Ivo Castro, "A elaboração da língua portuguesa no tempo do Infante D. Pedro", Biblos 69 (1993), Actas do Congresso Comemorativo do $6 .{ }^{\circ}$ centenário do Infante D. Pedro, Coimbra: Faculdade de Letras, 1993, pp. 97-127. 
identificada com a metafísica, às essências, ou às virtudes práticas (o que hoje se vem chamando applied philosophy) ${ }^{26}$. Isto explica por que se pode dizer que a filosofia que nascera nas praias da Jónia chegou a desaguar em Lisboa como uma prova de amor conjugal, haja em vista que a obra foi escrita a pedido da mulher, a rainha D. Leonor ${ }^{27}$. Será preciso reter que chegada a Portugal a filosofia atinge a sua última expressão ocidental continental e, daí, a necessária catapulta para uma deriva americana e ainda extremo-oriental?

Todavia seria empobrecedor não considerar aquele problema no quadro europeu ao qual pertence e no qual se valoriza. Como ficou explícito acima, não deixa de ser tristemente significativo que na obra tão tempestiva e valiosa que R. Imbach dedicou aos leigos na Idade Média seja mais do que patente uma confrangedora omissão a textos em língua portuguesa medieval. O condicionamento geográfico-linguístico não pode justificar a fatal ignorância dos nossos colegas europeus. Isto, não obstante, como pessoal e sustentadamente defendemos, ao longo da sua história, a filosofia pensada por nacionais nunca se ter eximido a expressar-se num evidenciado polilinguismo, muito anterior à koiné anglo-saxónica ora vigente. Concretizando, e num devir de quase quatrocentos anos, pelo menos o latim, o árabe, o castelhano, o francês, o italiano, o alemão, o romeno, o russo, o inglês, etc.

3.

O Leal Conselheiro de El-Rei D. Duarte é claramente uma obra não académica. $\mathrm{O}$ cronista Rui de Pina salienta esse facto apesar de atribuir ao rei um conhecimento parcial do trivium - da sua biblioteca constava a Dialectica de Aristóteles em língua latina ${ }^{28}$ - o amor pela ciência e pela leitura, e um autor preocupado com os "bens da alma" 29 . Alguém que, não podendo, é certo, encarnar o ideal platónico do filósofo-rei, reflecte outrossim, como veremos, o motivo mais peripatético do soberano-filósofo.

${ }^{26}$ Cf. J. de Carvalho, "Desenvolvimento da Filosofia em Portugal durante a Idade Média", in Id., Obra Completa, Lisboa: FCG, 1978, vol. I, p. 338, sobre os "quatro planos fundamentais" desse desenvolvimento.

${ }^{27}$ Sobre a mulher, em geral, vd. Conselheiro XLV: 175-77. Contraste-se, a título de curiosidade, M.S. de Carvalho, "Ontologia da condição feminina em Bernardo de Claraval" Revista Filosófica de Coimbra 12 (2003), pp. 305-328.

${ }^{28}$ Cf. Cartuxa c. 54, p. 206.

29 Rui de Pina, Chronica d'El-Rei D. Duarte, Lisboa, Mello d'Azevedo, 1901, c. III, p. 26. 
Manifesto da "situação" do pensar eduardino ${ }^{30}$, também o Livro da Ensinança, já considerado como o primeiro tratado de pedagogia desportiva $^{31}$, releva da atenção do pensamento sobre dimensões da práxis, perspectiva que o novo rei pode ter firmado no título que o seu próprio pai escreveu sobre a caça, o Livro da Montaria. Em ambas as obras sobressai a confluência da experiência com um contacto directo com a vida ${ }^{32}-$ ou como o próprio D. Duarte confessa no Leal Conselheiro, escrevendo mais segundo a experiência pessoal do que pela leitura ou ensino de letrados ${ }^{33}$ - o que já levou alguém a reconhecer, a propósito do Livro da Ensinança, como "nas bases empíricas do desporto medievo estava, latente, o germe dum possível e fecundo experimentalismo crítico"34. E assim pode ser. Lembremos que o dealbar da aventura marítima que caracteriza a cultura portuguesa e a sua contribuição para a Europa e o mundo é coeva da Geração de Avis e que uma noção própria de experiência (experiencialismo ${ }^{35}$ ) costuma ser vista como o resultado típico - e mais uma vez ignorado pelos especialistas narradores da história da ciência europeia, balizada entre os preconceitos de R. Descartes e de F. Bacon ${ }^{36}$ - dessa aventura expansionista nos alvores de um novo programa de globalização.

4.

Especialistas e diletantes têm privilegiado a relação do Leal Conselheiro com a cultura do seu país, sobressaindo aí, por banda de ambos, a análise de um aparentemente " intraduzível » como a saudade ${ }^{37}$, e a

${ }^{30}$ Sobre o problema, vd. primeiro o já citado A. Botelho, D. Duarte; e depois M.S. de Carvalho, "Em torno da Situação de Santo António no Pensamento Filosófico-Teológico", Itinerarium 41 (1995), pp. 161- 194.

31 S. Lima, "O desporto, o medo..." p. 982.

32 S. Lima, "O desporto e a experiência..." p. 1056.

33 Conselheiro Prol:9; ibid. XXVII:111

34 S. Lima, "O desporto e a experiência..." p. 1059.

${ }^{35}$ Cf. L.F. Barreto, "Do experiencialismo no Renascimento Português", in P. Calafate (dir.), História do Pensamento Filosófico Português, vol. II, Lisboa: Ed. Caminho, 1990, pp. 23-34.

36 O. T. de Almeida, “ 'Experiência a madre das cousas' - on the 'Revolution of Experience' in Sixteenth-Century Portuguese Maritime Discoveries and its Foundational Role in the Emergence of the Scientific Worldview", in M. Berbara \& K.A.E. Enenkel (ed.), Portuguese Humanism and the Republic of Letters, Leiden Boston: E.J.Brill, 2012, pp. 377-394. Ver também Ann M. Blair, "Organizations of Knowledge" in J. Hankins (ed.), The Cambridge Companion to Renaissance Philosophy, Cambridge: CUP, 2007, pp. 287-303, ignorando embora a nossa literatura.

${ }^{37}$ Cf. B. Cassin, Vocabulaire Européen des Philosophies. Dictionnaire des Intraduisibles, Paris: Seuil, 2004, para a crítica a esta obra, neste particular, vd. a recensão 
ocasião patológica que a suscitou, a melancolia ${ }^{38}$. Contudo, distintamente do que se considerou para o século XIV, em que nessa doença se reconhecia um mal de literatos, o sinal de se viver num tempo em que tudo de importante já havia sido escrito ${ }^{39}$, a melancolia que durante três anos acometeu D. Duarte era de natureza psíquica e somática. Uma patologia mais real do que literária decorrente de quem se viu, de repente, aos 22 anos, a braços com a gestão política do reino em tempos difíceis, como os da campanha de Ceuta. Enfim, responsabilidades acrescidas, que hoje levariam qualquer um de nós a evocar mais o stress do que o spleen. Sem dúvida que as páginas que o autor dedicou à análise da doença de que padeceu são merecedoras de atenção e têm um interesse insofismável ${ }^{40}$. O mesmo se diga, aliás, sobre as finas análises de recorte psicológico versando a tristeza e o receio, esta última emoção sobremaneira tratada no Livro da Ensinança.

Contudo, aqui interessar-nos-á a cura. Sublime melancolia, vê-lo-emos então, aquela mesma que, segundo a própria confissão do autor ${ }^{41}$, o tornou ainda mais alegre. Não por acaso tudo isto é acompanhado, também de modo explícito, por uma autoconsciência de inovar em tal matéria, pela escrita ${ }^{42}$, isto é, sem repetir os lugares-comuns do conhecido género literário conhecido como "espelho de reis" ${ }^{4}$. Se quiséssemos moderni-

publicada na Revista Filosófica de Coimbra 19 (2010), pp. 489-496. Para a crítica do assunto, embora num âmbito mais alargado, veja-se J. Barata-Moura, "Peso, pêsame, pesadelo - para um sopesamento (não saudosista) da saudade", in Id., Estudos de Filosofia Portuguesa, Lisboa: Caminho, 1988, pp. 195-221.

38 Veja-se suficiente bibliografia sobre a matéria na obra de J. Gama supracitada; o tema comparecera também, embora fugazmente, in Alfonso XI, Libro de la Montería... II c. 37, ed. pp. 296-298.

${ }^{39}$ Cf. J. Cerquiglini-Toulet, La couleur de la mélancolie. La fréquentation des livres au XIVe siècle, Paris: Hatier, 1993, p. 57 sg.; J. Huizinga, O declínio da Idade Média, trad., Lisboa : Ulisseia, ${ }^{2} 1985$, passim.

${ }^{40}$ Cf. Conselheiro XIX-XX. Vd. ainda Iona McCleery, "Both "illness and temptation of the enemy": melancholy, the medieval patient and the writings of King Duarte of Portugal (r. 1433-38)" Journal of Medieval Iberian Studies Vol. 1, No. 2 (June 2009), pp. 163-178 (devo esta referência ao colega Doutor J.F. Meirinhos, a quem agradeço).

41 Conselheiro XIX : 77.

42 Conselheiro LXXV: 274: “... ca nom vi sobre elo outra assi apartadamente scripta.”; sobre o progresso técnico, vd. Ensinança I c. 16, p. 32: «E eu achei hua nova maneira de mandar fazer strebeiras...», entre outros passos mais.

${ }^{43}$ Sobre a importância do género entre nós, vd. Nair Castro Soares, "Tratados de educação de príncipes em Portugal: um tema europeu”, in Ead. et alii (coord.), Latineuropa, latim e cultura neolatina no processo de construção da identidade europeia, Actas do Colóquio Internacional 9-10 de Novembro de 2006, Coimbra: Faculdade de Letras, 2008, pp. 173-199. 
zar o que aqui nos interessa teríamos de dizer que a biografia eduardina antecipa em carne e osso o que virá a ser a superação do pessimismo negativo schopenhaueriano pelo tom vital e afirmativo nietzscheano. Ora isto acontecerá de um modo em que se pode divisar alguma sistematicidade, o que passaremos a mostrar.

No discorrer pelo horizonte do contentamento, ou "folgança da razom", segundo o léxico do Livro da Ensinança ${ }^{44}$, deparamo-nos com as três esferas de consideração seguintes: do eu, dos outros, do mundo envolvente. Cada uma delas tem a sua correspondente no quadro da "ciência moral" aristotélica: "da própria pessoa" (a monóstica), do "regimento da casa" (a económica), do "reino e cidade" (a política) ${ }^{45}$. Na relação com os outros o princípio dominante é o de uma razão sensível porque, "consiirando a fraqueza dos homees", exercita o princípio do justo equilíbrio numa perspectiva nitidamente optimista ${ }^{46}$. No quanto concerne ao indivíduo (considerado na perspectiva do seu corpo, saber, condições e virtudes, entre outras dimensões mais) D. Duarte reconhece a possibilidade - melhor a necessidade - de um aperfeiçoamento ${ }^{47}$, que concitará a nossa atenção mais à frente. $\mathrm{E}$ na parte mais difícil, concernente àquilo que não se pode mudar, a fé numa ordem cujo definitivo horizonte escapa ao saber do Homem em vez de a escamotear, reforçará a convicção no saber e no poder humanos assente na "temperança de coraçom". Nas palavras do próprio D. Duarte: "buscando primeiro o reino de Deos e sua justiça, sempre com nosso poder e saber nos devemos trabalhar, quanto em nós for, d'acrecentarmos em todo nosso bem..."48 Isto merece ser pensado.

${ }^{44}$ Ensinança I c. 4, p.8. Sobre o contentamento, vd. Conselheiro LXXIII-LXXV.

45 Conselheiro CIII: 373; para a moral vd. G. Wieland, Ethica. Scientia practica. Die Anfänge der philosophischen Ethik im 13. Jahrhundert, Münster: Aschendorf 1981.

${ }^{46}$ Conselheiro LXXIV: 271: “... entrepetando os mais de seus feitos aa milhor parte."

${ }^{47}$ Conselheiro LXXIII:268: “... continuadamente pensar e obrar por mais bem acrecentarmos de tal guisa que nossa boa compreissom per boo regimento façamos melhor..." Um assinalável indício da importância da primeira pessoa pode ser encontrado no capítulo dedicado às falhas das virtudes, onde se pode ler o seguinte: "E per ua maneira me parece que homem pode conhecer com qual parte se mais tem: veja em seus feitos como mais vezes chama eu, e assi saibha que é maneira de seu viver" (Conselheiro LXXX:291).

48 Conselheiro LXXIV: 272 para a citação, e ibid. LXXV: 274. Os itálicos são nossos. Idêntico princípio e conselhos, que embora assentando num estoicismo estão longe de invalidar a transformação da paixão do contentamento em alegria racional balizada pela fé cristã, se hão-de ler por exemplo no Livro da Cartuxa: «Todo boo homem (...) deve (...) ser sempre contente do que há pois lhe vem por hordenança do senhor deus (...) Mes do que ouuer seja contente (...) crendo sempre que he muyto mais do que merece...» (Cartuxa c. 1, p. 7) E ainda: «sera sempre muyto contente pois entende que alem dos mereçymentos he sempre galardoado bem trautado e seruido e daquy lhe uira prazer continuado no sperito com muy boa tençom e charidade açerca de todos» (Cartuxa c 1, p. 8). 
Esta inusitada reivindicação do poder humano só pode depender de uma vontade regulada, da "espora da vontade e esforço pera obrar como deuemos o que por bem entendemos" 49 , agora nas palavras do confessor do rei, por este acolhidas em sua obra, o franciscano, et pour cause, frei Gil Lobo (+1437/8). É em nome da vontade, pois, que D. Duarte aconselhará "trabalharmos por seermos contentes de cada cousa segundo seu tempo e razom..." 50 . No triângulo que configura a antropologia eduardina - saber/querer/poder -, temos do lado do saber a virtude da prudência (juntamente com a memória e o entender), do lado do querer a virtude da justiça, e do lado do poder a virtude da temperança e da fortaleza, estas consideradas mais necessárias aos senhores ${ }^{51}$. Com o exercício da justiça interconectam-se a temperança e a fortaleza ${ }^{52}$, e não será mero acaso que ao falar das virtudes "principais" D. Duarte publicite bem o seu saber livresco ${ }^{53}$. O tema era no mínimo difícil. Problemático, mesmo. Cita, em primeiro lugar, o Regimento de Príncipes de Egídio Romano, depois as Eticas de Aristóteles (no resumo de Afonso de Cartagena), e ainda o Pomar das Virtudes do franciscano André de Pace, e ainda Valério Máximo, Cícero (De Oficiis) e, naturalmente, as Instituições e as Colações de João Cassiano, além do crucial nesta matéria, o pseudo-aristotélico Segredo dos Segredos ${ }^{54}$. Uns textos mais importantes do que outros no

${ }^{49}$ Cartuxa c. 25 , p. 144.

50 Conselheiro LXXV: 274; vd. M. C. Pacheco, "Intelecto prático e vontade em D. Duarte, rei de Portugal", Revista da Faculdade de Letras - Porto (1995-96), pp. 33-42.

${ }^{51}$ Conselheiro L: 201.

52 Cf. Conselheiro LX: 243-44.

${ }^{53}$ Cf. Conselheiro L-LIX; "filosofalmente", como o autor escreve, as virtudes chamadas "principais" são: prudência, temperança, fortaleza e bom conselho. Também no tratamento da primeira delas, cujo "grande fundamento é da mui perfeita prudência, nom se reger per seus desejos e paixões, mas per aquelo que nosso boo entender demostra, ou per soficientes pessoas, quando convem, nos é conselhado" (Conselheiro LI: 205), D. Duarte alardeia o seu conhecimento livresco, a saber: Regimento dos Príncipes, a Moral e a Política de Aristóteles, seguindo-se ainda uma referência ao Pomar das Virtudes e a Vegécio no Livro da Cavalaria, de novo Aristóteles nos Tópicos e o Policrático, mais uma citação não identificada de Platão (República?), complementada pela Consolação da Filosofia, de novo Policrático e a Ética VI de Aristóteles, e mais adiante Retórica II de Aristóteles e de novo a Moral VI, continuando a remeter para o Regimento de Príncipes, o Tratado da Providência de Séneca, o Segredo dos Segredos e o livro das Colações. Mais adiante o De Officiis de Túlio, título cuja tradução no que toca à prudência merece um capítulo por si só, o mesmo merecendo o doutor Diego Afonso, que a definira como "ua dereita razom, pera obrar as cousas singulares, nascida da experiencia das cousas passadas, situada em natural desposiçom e sguardante nas cousas viindoiras, proveendo ao que pode acontecer quanto em nosso poder é" (Conselheiro LVIX: 241).

54 Cf. Pseudo-Aristóteles, Segredo dos Segredos, ed. de A. Moreira de Sá, Lisboa, Faculdade de Letras da Universidade de Lisboa, 1960; vd. J. de Carvalho, "O 'Secreto 
que às duas virtudes principais interessa, sublinhe-se ainda o facto de D. Duarte acompanhar a tópica da alma sensitiva que atribui a temperança à faculdade concupiscente (o "desejador") e a fortaleza à irascível ${ }^{55}$. Do seu confessor Gil Lobo poderia ter sabido desta tópica ${ }^{56}$, mas a experiência pessoal ou autobiográfica do poder subjectivamente considerado - continuamos a pensar na cura - superará toda esta herança cultural e livresca em nítido contraponto a essa figura decadente da vontade - "quebrar-se a vontade", escreve mesmo ${ }^{57}$ - que é a melancolia. Confrontamo-nos destafeita com três instâncias ecológicas, porque concatenadas pela expansão do eu, do poder/poderio (vegetativo, sensitivo e intelectivo): “o poderio de crescer e gouernar requere comer bever dormyr (...) manter o corpo em saude"; "o poder de sentyr demanda cousas lygeiras de pasar com prazer com toda deleitação da uontade..."; "e o poder do entender requere bem fazer e folgança em cuydar de o por em obra..." 58 . O fito é, então, simples: afastarmo-nos da má tristeza - "e cada uma destas partes compre reger muyto bem e discretamente aquel que de tristeza se quer afastar..."59 - motivo que não perde de vista o horizonte teológico crucial de um crescendo na ledice, de um aumento de ser até à bem-aventurança cristã: "viuereis ledo em esta vida, e com esperança de mayor lediçe do que há de vir" 60 Não sem razão cristã testemunhava Rui de Pina que o Rei "foi homem allegre e de gracioso recebimento" 61.

Nos antípodas do contentamento está a "aspereza", pelo que esta suscita de tristeza e de ingratidão. Contudo também ela só pode ser combatida com "o dito de salomon alegrar se e fazer bem" 62 . Num sinal

de los secretos de astrologia' do Infante D. Henrique (rectificação), O Instituto 93 (1939), pp. 345-357.

55 Conselheiro VI: 35.

${ }^{56}$ Cf. Cartuxa c. 26, p. 145. Conselheiro VI: 32.

57 Conselheiro XIX: 74.

58 Conselheiro XXIV: 92.

59 Cartuxa c. 3, p. 22. Como se disse já ao pecado da tristeza dá-se muita atenção (citando-se Cassiano, Livro dos Estabelecimentos e das Colações, que a considerava "pecado principal" ou "começo de morte"): de um ponto de vista estrito em cinco capítulos, em sentido lato oito capítulos, sempre no Leal Conselheiro. Havendo duas maneiras de tristezas, a que vem da virtude (à qual ainda voltaremos - vd. nota 83) e a que vem do pecado (Conselheiro XXI:84-85), esta última é divisível no sentimento de frustração e no queixume ou desespero; quanto à má tristeza, esta tem seis tipos de origens: medo da morte, sanha por vingar, desejo não satisfeito, nojo, humor melancólico, convivência com tristes ou desesperança (Conselheiro XVIII: 71-72).

${ }^{60}$ Cartuxa c 3, p. 24.

61 J.M. Piel, "Prefácio", in Leal Conselheiro..., p. XXVII.

62 Cartuxa c 1, p. 9. 
claro do realismo da experiência da ultrapassagem da melancolia pela alegria temos ainda uma abundante abordagem física pormenorizada. Sendo certo que por aquela circula o motivo tradicional da harmonização do platonismo (República) com o aristotelismo (Ética Nicomaqueia), nomeadamente nos tópicos obrigatórios sobre a imagem do governante ideal, com facilidade se topa com uma surpreendente evocação experiencial pessoal e cultural local que gravitam em volta da alegria assente na dimensão mais elementar da física. Embora sem desconhecer que a tristeza não é só física, por razão dela sempre trazer "desordenança do corpo"63 - "sobrepojamento de alguns humores que desgouernão o corpo (...) e a tristeza não he daly solamente" 64 -, no conselho ao seu irmão D. Pedro a afastar-se da tristeza, a "uyuer em folgança", D. Duarte não descuida o equilíbrio do corpo nesse esforço ${ }^{65}$. Também D. Henrique, a fim de motivar o irmão rei para a "alegria e o prazer da guerra", aludiu ao mesmo fim, relativo embora, da vida, qual a alegria do corpo que particulariza nos termos de comer, beber, dormir, cantar, rir, ver, ouvir, a companhia de mulheres, casar, motejar, falar ${ }^{66}$. Justar, dançar e cavalgar - eis o que no Livro da Cartuxa também se considera ser gerador de alegria ${ }^{67}$. Acresce que ninguém poderia ignorar o reforço social desta dimensão antropológica e social, qual a do ambiente de "festas jogos e folganças honestas" como marca da corte de seu pai ${ }^{68}$. Sabido é que D. João estendia o jogo à totalidade do ser humano - i.e. do sentir ao entender - e recomendava-o a demais suseranos a título de comportamento "exemplar" "69. Finalmente, não deixa de ser saliente o modo mais físico como D. Duarte elogia o Condestável D. Nuno: "boa disposição do corpo e rostro e força e compreisão e manhas corporães"70. No horizonte aristocrático do Homem superior, um homem santo não poderia também deixar de ser dotado de um corpo são.

${ }^{63}$ Cartuxa c. 3 , p. 24.

${ }^{64}$ Cartuxa c. 3, p. 23.

${ }^{65}$ Cartuxa c. 3, pp. 22-23.

${ }^{66}$ Cartuxa c. 20, p. 117.

${ }^{67}$ Cartuxa I c. 4, pp. 8-9. Infelizmente esta obra não chega a abordar as $11^{\mathrm{a}}$ e $15^{\mathrm{a}}$ partes atinentes respectivamente sobre a fermosura em cavalgar e sobre conhecer, guardar e acrescentar as bondades (Ensinança, Prólogo, pp. 13-14).

${ }^{68}$ Cartuxa c. 18, p. 106. Sobre a matéria dos jogos, vd. Livro dos Ofícios... I c. 37, ed. pp. 803-04.

${ }^{69}$ D. João I, Libro de la Montería... I c. 1, ed.p. 9: “....assacarom os antiguos joguos de tres maneiras, per que se pudesse recrear o entender...”; Id., ibid. I c. 2, ed. p. 11-14, e mormente, p. 12, sobre os reis que devem ser ledos para que os súbditos folguem com isso.

${ }^{70}$ Cartuxa c. 61 , p. 226; sobre D. Nuno Álvares Pereira vd. também Conselheiro XX: 79 . 
5.

Acolhendo o princípio da totalidade, e assim assumindo-se deveras como pensador, D. Duarte enquadrará a folgança nas três aristotélicas dimensões referidas ("tres poderes ordenados"71). "Creçer e gouernar o corpo, sentyr e entender", configuram um vector antropológico que nos lembra a vexata quaestio da relação vontade/intelecto, obrigando-nos a verificar como D. Duarte tem sobre este tópico uma posição muitíssimo pessoal.

Não há dúvida nenhuma acerca do lastro intelectualista aristotélico-tomista que permeia o Leal Conselheiro. Nesta linha, mesmo noutras obras, D. Duarte resume matéria sobre o entendimento, como principal virtude da alma, caracterizada não pela força nem pelo sentir, mas pela razão. Mas não podemos iludir uma antropologia que não se concerta na totalidade com o intelectualismo puro e simples. Assim, à maneira de S. Agostinho, o autor faz notar que na "alma ha muytos offiçios e por cada offiçio ha seu direito nome", a saber: alma, se der vida ao corpo do homem, e depois vontade, e razão, e sentimento, e sapientia, e entendimento, este "a mayor e mais alta partida do homem qua por ele auemos razon e conheçymento e he chamado o homem imagem de deus"72. Isto assinala a crise da tópica psicológica aristotélica e depois do que apontámos sobre o "trabalho" que habilita ao acrescentamento do bem ${ }^{73}$, salta-nos inevitavelmente à lembrança o modo similar, augustinista no seu tom e ritmo, como G.B. Vico $(+1744)$ chegará a identificar a natureza do Homem com as três faculdades, nosse, velle e esse/posse ${ }^{74}$. De notar que à boa maneira das Confissões também D. Duarte recorre a uma metáfora arquitectónica para falar do eu - o "oratorio como casa do coraçom - no sentido de uma clara introspecção ou ascética moderna - no oratório cada um se aparta "pera rezar, leer boos livros, e pensar em virtuosos cuidados"75

${ }^{71}$ Cartuxa c. 3 , p. 22.

72 Cartuxa c. 19, p. 114. Cf. Agostinho, Conf. XIII xi 12; Id., De Trinitate XI iii 6.

$73 \mathrm{Vd}$. acima nota 47.

${ }^{74}$ Cf. Vita de G.-B. Vico scritta da sé medesimo (apud J. Chaix-Ruy, J.-B. Vico, Oeuvres Choisies, Paris: PUF, 1946, p. 18).

75 Conselheiro LXXXI: 294. Importa reter o modo como se pode ler em S. Agostinho a invenção moderna filosófica do eu, cf. G. B. Mathews, Santo Agostinho. Trad. do inglês, Lisboa: Ed. 70, 2008. Por outro lado, seria talvez necessário lembrar a metáfora das "moradas" a que S. Teresa há-de recorrer - vd. Santa Teresa de Jesus. Castillo interior o las Moradas. Ver. textual y notas J. Vicente Rodríguez, Madrid: Editorial de Espiritualidad, ${ }^{8} 2006$ - que lembra uma outra metáfora augustinista, sobre a memória, nas Confissões $\mathrm{X}$ viii 12 . 
Apesar de algumas poucas tergiversações ${ }^{76}$, é preciso ter em mente que, segundo D. Duarte, o "entendimento" se distingue do "entender". Este corresponde às faculdades da filosofia aristotélica - o nous -, agente, possível, especulativo e prático, sobre as quais D. Duarte acrescenta ter lido um tratado ${ }^{77}$. Aquele condiz com uma tópica mais ampla que, nas suas sete partes constitui a maneira pessoal como o Rei acolheu a complexa tradição platónico-aristotélica das qualidades que devem enformar todo o governante: a aprendizagem, a lembrança, o juízo, a invenção, a declaração, a execução, a firmeza e a perseverança ${ }^{78}$. Falamos pois do Homem integral e superior pelo que acabamos de topar com os lugares-comuns da phrónesis ético-política: para um "boo entendimento" requer-se grande memória e boa vontade ${ }^{79}$ e ainda as virtudes do coração aplicadas em quatro regras, a saber: o conhecimento da graça de Deus; a temperança no comer, no beber e na vida; não se deixar vencer por paixões de amor e temor; o desejo de ter e prezar todas as partes do entendimento, pois "muito se percalça do que rijo e continuadamente é desejado" 80 . Todavia, e na nossa interpretação, enquadradas pela boa conversação, pela leitu$\mathrm{ra}-\mathrm{o}$ prazer da leitura concita páginas que agradariam a A. Manguel ${ }^{81}$ -, sobretudo pelo exercício do entender e da experiência sobre o que se deve fazer, a maioria das sete partes do entendimento dizem respeito ao saber, tal como o querer há-de provir da vontade e o poder, do corpo, da fazenda e do tempo ${ }^{82}$. Em suma, se concebermos a melancolia como aquela forma de tristeza caracterizada pela fixação reflexiva do sujeito na caducidade, ou seja, como uma paixão descendente ou decadente constitutiva de uma existência imprópria ou meramente singular ${ }^{83}$, o relevo

${ }^{76}$ No Livro da Cartuxa 24 (p. 142-43) lê-se entender e não entendimento: apreensiva, retentiva, judicativa, inventiva, declarativa, executiva e perseverança (constância e firmeza).

77 Cf. Conselheiro II: 19.

78 Conselheiro I: 13-18. Em português, o leitor poderá obter uma clara informação sobre a tradição filosófica das qualidades do governante em Rosalie Helena de Souza Pereira, Averróis. A Arte de Governar, São Paulo, Perspectiva, 2012, pp. 196-208.

${ }^{79}$ Conselheiro II: 19. Deve haver uma adaptação entre as partes do entendimento e as sete idades da vida, numa expectativa de oitenta anos! (ibid. I:16), embora a repartição dos 70 anos que D. Duarte segue seja diferente da dos letrados e dos legistas (Conselheiro I:17; vd. também ibid. IV:27-28).

${ }^{80}$ Conselheiro I: 15.

${ }^{81}$ Cartuxa c. 29, p. 149; Cf. também Conselheiro Prólogo: 10 e ibid. XXVII:108, 110-11. Cf. A. Manguel, Uma história da Leitura, trad., Lisboa: Editorial Presença, 1998.

82 Cf. Conselheiro IX: 40.

${ }^{83}$ Cf. E. Trias, Filosofia del futuro, Barcelona: Ariel, 1983, pp. 47, 77 e passim. De notar que a boa tristeza, dominada "por desejo de perfeiçom", e portanto podendo ser apanágio do Homem superior, é, em rigor, uma falsa tristeza - dizemos nós - dado o facto de ser "leda pólo seu proveito" retendo "toda a graciosidade e afabilidade" e, sobretudo, 
dado à sua superação definitiva pelo trabalho do entendimento - "o saber e as virtudes com trabalho se aprendem, guardam e seguem" 84 - anuncia modernamente uma existência própria, um singular propriamente dito.

Diversamente do mero singular, o singular propriamente dito, o eu que se aperfeiçoa regendo-se pela "lealdade" funda-se no elogio da vontade perfeita ou virtuosa. Esta assenta nalgumas das dimensões da tópica do entendimento mas ultrapassa-as. Tendo como horizonte a lição teleológica de Raimundo Llull sobre "haver primeira teençom as cousas mais excelentes das virtudes" $"$, a terceira forma da vontade, aquela que o Homem partilha com os Anjos, diz respeito às virtudes e à consideração do passado, presente e futuro ${ }^{86}$. Também é certo que, segundo o Livro das Colações ${ }^{87}$, a última das quatro formas em que a vontade se divide "todalas cousas faz ou leixa de fazer per exame de entender e razom" 88 . Contudo, senhor entre as restantes formas ou dimensões da vontade, porque nela reside o pecado e a virtude, mormente a virtude da "geeral justiça" 89 , não se pode interpretar essa vontade como se fora alheia ao horizonte do entendimento. Pelo contrário, haja em vista que nele se vê a imagem de Deus $^{90}$ e, por isso, a vontade e o entendimento só sobrevivem conjuntamente. Além da enumeração "das virtudes que se requerem a uu boo julgador", D. Duarte cuidará mesmo em apresentar-nos auto-testemunhos práticos do seu privilégio decisor ${ }^{91}$, do querer da vontade (justiça) que nos capacita para uma vida autêntica ou inautêntica. Como não podia deixar de ser, isto comporta uma figuração política claramente comprometida.

por ter em si "todolos fruitos do sprito", a saber; "caridade, plazer, paz, longanimidade, bondade, benignidade, fe, mansidõe, continência" (Conselheiro XVIII: 70).

84 Conselheiro I: 16.

${ }^{85}$ Conselheiro LXXXI: 297. A presença de Raimundo Lull ou dois lulistas é patente no Leal Conselheiro, vd. entre outros passos mais: XXXVI, LXV. Para uma interpretação simultaneamente popular e racional da proposta lulista, vd. o nosso Raimundo Llull. Vida Coetânea. Introdução, tradução, anotações, quadros e índices de M. S. de Carvalho, Coimbra: Ariadne Ed., 2004.

${ }^{86}$ Conselheiro VI: 34 e VII: 37. O caminho da discrição (discliçom), o "verdadeiro siso" em linguagem, consiste em deixarmo-nos governar pela quarta vontade (Conselheiro III:24).

87 J.M. Piel identifica Collationes Patrum IV c 9 e 12, de João Cassiano, traduzidas por Frei Nicolau de Alcobaça (vd. Livro da Ensinança p. 89).

${ }^{88}$ Conselheiro III: 23. Eis a regra: "Deve seer, pera vivermos virtuosamente, inclinada e concordada sempre a parte do entender e razom, ca todo que per scolhimento se faz, per voontade o fazemos" (Conselheiro VI:35).

89 Conselheiro VI: 35. De notar que, ontologicamente considerada (Conselheiro LXXX: 289) embora, a justiça pode ser pervertida (falicimento) pelo "desejo de vingança, conseguimento da voontade e de vão nome..."

90 Cf. supra nota 72.

91 Conselheiro LX: 243-47 e VI: 34, respectivamente. 
À semelhança da aplicação política da metáfora da grande cadeia do ser que o seu irmão recolheu na Virtuosa Benfeitoria nos interesses da causa e da casa de Avis, ao Leal Conselheiro não escapa o horizonte de uma antropologia política que permite a identificação dos homens superiores como aqueles que detêm grande e subtil entender e vontade justa e direita $^{92}$. Estes últimos, os mais perfeitos, são chamados "sesudos, prudentes, discretos e de boo entendimento" 93 .

6.

Não sendo D. Duarte um académico impõe-se-nos, então, a sua qualidade de soberano-filósofo-leigo ${ }^{94}$. Já o dissemos. Com tantos outros, aliás, embora não sempre por idênticas razões. Julgamos agora termo-nos deparado com um ritmo triádico organizador de uma coerência no seu conteúdo pensado, capaz de consubstanciar um perfil filosófico e um programa concreto. Curiosamente, esse ritmo pode mesmo corresponder a um ternário identificado por Sílvio Lima e que não é difícil descortinar no Leal Conselheiro: graças ao querer e ao saber chegaremos ao poder ${ }^{95}$. Esta convicção pode crescer quando, primeiro, no Livro da Ensinança, D. Duarte parece esboçar um curriculum pedagógico para os seus leigos leitores aristocratas. Começando pela aprendizagem do latim, preconiza-se depois a filosofia moral, para se concluir o ciclo da pedagogia com as ciências da guerra ${ }^{96}$. Uma pedagogia da guerra? Não, forçosamente ou exclusivamente. Tratar-se-á antes da vida activa do espírito na sua relação com a liberdade na acepção que lhe há-de conferir Hannah Arendt ${ }^{97}$, mutatis mutandis; dito de uma outra maneira: uma antropologia deter-

92 Conselheiro VIII: 38-39. Desde o Prólogo que o autor esclarece que a obra se destina "principalmente" aos homens da corte (cf Conselheiro Prol:11). Sobre o tema, mas para a obra do irmão, vd. N. C. Soares, "A 'Virtuosa Benfeitoria', primeiro tratado de príncipes em portuguêss", Biblos. Revista da Faculdade de Letras, Actas do Congresso Comemorativo do $6 .^{\circ}$ centenário do Infante D. Pedro, Coimbra: Faculdade de Letras, 1993, p. 289-314.

93 Conselheiro VIII: 39 e também ibid. IX: 41

94 Retenha-se uma declaração sobre o lugar de onde D. Duarte compreenderia o trabalho filosófico: "pensando das cousas como som, e a maneira que sobr'elas deve teer com as outras circunstancias a esto perteencentes" (Conselheiro I:14)

95 Cf. S. Lima, «O desporto, o medo...» p. 984. Os sublinhados são do autor.

96 Ensinança V c. 15, pp. 120-21. Embora num horizonte mais amplo, vd. sobre o tema J.G. Monteiro, A guerra em Portugal nos finais da Idade Média, Lisboa: Notícias, 1998. É aliás precisamente por causa da guerra que lemos algumas páginas com o sabor curioso também da moda sobre o que se deve vestir para a equitação (Ensinança I c. 18, pp. 35-36).

${ }^{97}$ H. Arendt, A Vida do Espírito. Vol. II: Querer. Trad., Lisboa: Ed. Piaget, 2000. 
minada pela ideia de um Homem superior pensado também a partir do "Eu-quero". Logo na abertura do Livro da Ensinança D. Duarte justifica que "ainda que o poder e querer nom sejam verdadeiramente pera ensynar, por que se gaançom per natureza e graça special (...), screvo sobr'elo por espertar o desejo e mostrar o poder que geeralmente avemos, se voontade e saber ouvermos." 98 Diríamos, sem contudo sermos taxativo, e muito menos adiabático pela precisa razão da justificativa acabada de aludir pelo próprio autor: o saber do lado do trivium; o querer, como contribuição da filosofia moral; o poder, originando-se na prática das actividades físicas. A própria educação física do corpo $^{99}$. Embora esta tríplice cisão seja algo incompatível com a estrutura do Livro da Ensinança - a sua primeira parte é dedicada à vontade, a segunda ao poder, e a terceira aos aconselhamentos técnicos ("16 avysamentos pryncipaaes") - não deixa de resultar que a amplitude do universo da vida activa (vida autiva ${ }^{100}$ ) requisita aqueles três domínios sem fronteiras inultrapassáveis, pelo que à "fortaleza do corpo e do coração" se deve agregar o ser-se "sabedores per boas speriencias e natural entender" a fim de que "ajam saber certo e verdadeiro do que devem querer e fazer obrar, contradizer e soportar em sy e nas obras de fora"101. Sobretudo, e como observou um sensível intérprete coimbrão, "D. Duarte crê que mediante a graça de Deus, a ciência educativa e a força da vontade, se pode alterar muito na natureza humana" 102 , razão pela qual julgamos ver modificadas as palavras iniciais da Metafísica de Aristóteles, quando o rei escreve, numa orientação que privilegia a razão prática: “...todollos homens naturalmente desejam sua honrra, proveito e boo prazer..." 103 . As palavras com as quais se promove a possibilidade de novidade e autêntica recriação são claras : "E posto que se diga que nom podemos mudar as cousas da natureza, eu tenho que per boo entender e geeral boa vontade os homees enmendam muyto, com a graça de deos, em os seus naturaaes fallecymentos, e acrecentam nas virtudes". Imediatamente, comparece o topos do "socratismo cristão",

${ }^{98}$ Ensinança, Prólogo, p. 2.

${ }^{99}$ Ensinança V c. 15, p.120: «... consiirem que seus corpos som assy como suas herdades, as quaaes, se nom forem bem aproveitadas e lavradas, daróm de sua natureza spinhos e cardos e outras ervas de pouco vallor; e com trabalho e rompimento e aproveitamento dellas dam taaes fruitos de que principalmente em esta vida avemos nossa governança.»

100 Conselheiro LXXXV: 307: "Por quanto aos que teem vida autiva convem reguardar as cinco fiis suso scriptas, scilicet por haver saude, gloria percalçar, e manteer honra com verdadeiro boo nome, continuar em geeral e governar bem a fazenda, viver em boa ledice, certas regras em ela devem ser guardadas."

101 Ensinança I c. 3, p. 8.

102 S. Lima, «O desporto, o medo...» p. 983. O sublinhado é do autor.

103 Ensinança I c. 1, p. 4. Cf. Aristóteles, Metaph. A 1 980a 20. 
consolidando uma gramática do progresso antropológico: "E porem cada huu deve trabalhar por sse conhecer, e no bem que naturalmente recebeo se manter e acrecentar, e nos fallymentos enmendar e correger." $104 \mathrm{Um}$ bom testemunho do homem que a si mesmo se supera é - repetimos - a explícita cura da melancolia, e bem assim o apreço que o autor nutre pela sua "exemplar" ou "especular" experiência pessoal ${ }^{105}$.

\section{7.}

Concluamos. Permita-se-nos a liberdade de glosarmos ou adaptarmos uma célebre equação queirosiana, ou melhor, da personagem de Jacinto em A Cidade e as Serras (1901), no sentido de também nós forjarmos o que poderia ser a inusitada equação antropológica de D. Duarte: Saber + Querer $=$ Poder. Do que acabámos de dizer decorre pelo menos uma dificuldade no respeitante ao que aqui denominámos a antropologia do Homem superior. De facto, por um lado, o rei confessa que o Querer e o Poder não entram no campo da pedagogia, antes resultando daquelas determinações alegadamente naturais com que a aristocracia justificava o seu poder, objectivamente considerado (o poder político). Mas, por outro lado, quer o Leal Conselheiro, quer o Livro da Ensinança afirmam a possibilidade/necessidade do poder, subjectivamente considerado (o poder da vontade, o Eu-quero), resultado do querer ou da vontade como vector ou coroamento do complexo entendimento. Neste último aspecto D. Duarte é nitidamente um homem moderno, embora sem irmos ao ponto de sustentar que essa modernidade se estenderia à esfera do político, isto é, ao caso em que o Eu-quero daria acesso ao poder objectivamente considerado. De facto, nada no-lo permite sustentar, não sendo contudo difícil perceber-se como deverá caber ao poder/poderio (justiça) preencher as intermitências do querer (vontade). Mais ainda, e sensivelmente para a casa de Avis, em razão da sucessão dinástica: é o soberano que se deve tornar filósofo, de certa maneira, e não o filósofo devir rei; mas também aqui uma nova dificuldade aflora, pois o Homem integral e singular, propriamente dito, é-o radicalmente ou ontologicamente no plano ético antes mesmo de qualquer inauguração do Político ${ }^{106}$. Hoje em dia - e como é demasiadamente óbvio - se podemos considerar como de urgente reprogramação

${ }^{104}$ Ensinança II c. 1, p. 45; também Conselheiro XLIX. Os sublinhados são nossos. Sobre o denominado "socratismo cristão", vd. E. Gilson, O espirito da filosofia medieval, trad. São Paulo: Martins Fontes, 2006, p. 284 (o original é de 1932).

105 Cf. Ensinança III c. 9, p. 22 e ibid. IV c. 12, p. 109 entre outros mais.

$106 \mathrm{O}$ que acima ficou dito conduz-nos irrefragavelmente a perguntar se às quatro antinomias do poder que José Gil (Corpo, Espaço e Poder, Lisboa, Litoral Ed., 1988, pp. 20sg) elencou, não deveríamos acrescentar, pelo menos, uma quinta, referente à "ontologia do poder", no sentido débil da expressão, ou seja, sobre a "configuração ou encarnação do poder". 
um fundamento ética para a política, já nos parece inaceitável, e mesmo incompatível com os ideais democráticos, qualquer equivalência, para já não dizer "justificação", entre posição política, funcional, e superioridade humana, ontológica. Mas, dito isto, continua a ser verdadeiro, a nosso ver, o facto de somente pela Ética ser possível pensar-se, no quadro de uma radical equipolência ontológica, o Homem Superior.

Assim, tudo nos permite dizer que o poder exaltado no Leal Conselheiro ou $A B C$ da Lealdade 107 é o subjectivo, o poder do eu autêntico, do singular propriamente dito, habitado e habilitado pelo quase oximoro de uma sensação metafísica - "o meu sentido entendo"108. E eis então como o Eu-quero (ego volo) poderia ter sido uma alternativa ao ego cogito! Entenda-se bem: o poder dependente do domínio das faculdades - vegetativa, sensitiva (concupiscente e irascível), intelectiva -, o poder que cultiva o regime do corpo, que é sensível à temporalidade, que coincide com as virtudes principais e, sobretudo, sob o signo da lealdade, o que constrói verdadeiramente o eu mediante uma articulação singular da filosofia moral - "seguindo realmente as virtudes, scilicet concordar os dictos de Nosso Senhor e o que os sabedores católicos e filosafos disserom com os sentidos de nosso coraçom, e practica que nos outros conhecemos" 109 . Certamente, o Eu-quero nada é se nele não estiverem implicadas a prudência e a justiça enquanto expressões societárias da "moral e virtuosa sciencia" 110 . Entretanto, de um ponto de vista biográfico ou pessoal, uma vitória sobre a melancolia coincide com essa implicação ${ }^{111}$. É assim que o Eu autêntico alcança a alegria racional.

107 Conselheiro Prol.: 9, ibid. CIII: 373. Como o autor explicitamente reconhece (ibid. Prol.: 12), para a sua metodologia literária segue o modelo do Livro do Amante de João Gower (+ 1408), tradução portuguesa da Confessio Amantis a instâncias de D. João I (vd. J.M. Piel, Leal Conselheiro, p. 7, n. 1); vd. ainda A.C. Ocaña, "La traducción portuguesa de la 'Confessio Amantis' de John Gower”, Euphrosyne 23 (1995), pp. 457-466.

108 Conselheiro CIII: 374.

109 Conselheiro CIII: 374. O sublinhado é nosso. Um pouco mais acima no mesmo lugar, D. Duarte escrevera, esclarecendo: "E pera guardar esta lealdade acerca de Nosso Senhor, o mais que tenho em este trautado scripto esto conselha, ensina e avisa; ca eu mesturo moral filosafia, de que algua parte vi, com seus mandatos e dictos dos sanctos e católicos sabedores, que a mais perfeitamente que os filosafos entenderom, e derom acabadas ensinanças, consiirando o que delo naturalmente per meu sentido entendo, e do que vejo, ouço e conheço em minha maneira de viver e dos outros."

110 Conselheiro Prol.: 11.

111 Cf. Conselheiro XX: 78. 